\title{
Synthesis of Arylseleno-1,2,3-triazoles via Copper Catalyzed 1,3-Dipolar Cycloadditions of Arylseleno Azides with Alkynes
}

\author{
Natália Seus, Maiara T. Saraiva, Eder J. Lenardão, Gelson Perin, Raquel G. Jacob, \\ Samuel R. Mendes and Diego Alves*
}

Laboratório de Síntese Orgânica Limpa, Universidade Federal de Pelotas, UFPel, Pelotas, RS, Brasil.

*e-mail corresponding author: diego.alves@ufpel.edu.br

Keywords: Cycloadition, 1,2,3- triazoles, selenides

\section{INTRODUCTION}

Organoselenium compounds are attractive synthetic targets because of their selective reactions ${ }^{1}$ and association with biological activities. ${ }^{2}$ Selenides or diselenides containing nitrogen atoms in their structure are a special class of these compounds and they have been employed in various organic transformations, for instance, asymmetric synthesis. ${ }^{3}$ Consequently, the search of new and efficient methods for the preparation of highly functionalized organoselenium compounds, remains a challenge in organic chemistry. Although the synthesis of selenium-containing triazole compounds has been reported, ${ }^{4}$ no reaction using a copper catalyzed protocol has been described so far. This fact encouraged us to explore the use of arylseleno azides 1 in the copper-catalyzed 1,3-dipolar cycloaddition with alkynes 2 to obtain arylseleno1,2,3-triazoles 3 .

\section{RESULTS AND DISCUSSION}

Our initial studies have focused on the development of an optimum set of reaction conditions. Thus, a mixture of arylseleno azide 1a and phenylacetylene $\mathbf{2 a}$, were reacted under air atmosphere, utilizing different copper catalyst, solvent systems and additives. The optimum conditions for the this cycloaddition reaction were found to be the use arylseleno azide $\mathbf{1}(0.25 \mathrm{mmol})$, phenylacetylene $\mathbf{2 a}$ ( $0.25 \mathrm{mmol}), \mathrm{Cu}(\mathrm{OAc})_{2}$ as catalyst (5 mol\%), sodium ascorbate (NaAsc) as additive (10 mol\%), in a mixture of $\mathrm{THF} / \mathrm{H}_{2} \mathrm{O}(1: 1)$. The reaction was carried out at room temperature for $8 \mathrm{~h}$ under air atmosphere affording the desired arylseleno-1,2,3triazole $3 \mathbf{a}$ in excellent yield (Figure 1).

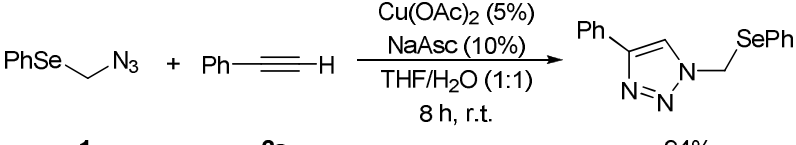

$$
\begin{aligned}
& 1 \quad 2 a \quad 94 \%
\end{aligned}
$$

Figure 1. Optimized reaction condition

Under the optimized condition, a variety of terminal alkynes reacted smoothly with arylseleno azide 1 to produce arylseleno-1,2,3-triazoles $\mathbf{3 a - j}$ in good to excellent yields (Table 1).
Table 1. Arylseleno-1,2,3-triazoles 3a-x obtained.

Entry

${ }^{*}$ Yields are given for isolated products.

\section{CONCLUSION}

In summary, we have described of the use of organoselenium compounds in the copper catalyzed synthesis of 1,2,3-triazoles. Arylseleno-1,2,3triazoles 3 were prepared in good to excellent yields under mild conditions via reaction arylseleno azides 1 with alkynes 2.

\section{ACKNOWLEDGEMENTS}

CNPq, CAPES, FAPERGS (ARD 10/0130-3) and FINEP.

\section{REFERENCES}

(a) Perin, G.; Lenardão, E. J.; Jacob, R. G.; Panatieri, R. B. Chem. Rev. 2009, 109, 1277. (b) Braga, A. L.; Lüdtke, D, S.; Vargas, F. Curr. Org. Chem. 2006, 10, 1921.

(a) Nogueira, C. W.; Zeni, G.; Rocha, J. B. T. Chem. Rev. 2004, 104, 6255. (b) Alberto, E. E.; Nascimento, V.; Braga, A. L. J. Braz. Chem. Soc. 2010, 21, 2032.

${ }^{3}$ Freudendahl, D. M.; Shahzad, S. A.; Wirth, T. Eur. J. Org. Chem. 2009 1649.

${ }^{4}$ (a) Back, T. G.; Bethell, R. J.; Parvez, M.; Taylor, J. A.; Wehrli, D. J. Org. Chem. 1999, 64, 7426. (b) Tiecco, M.; Testaferri, L.; Santi, C.; Tomassini, C.; Marini, F.; Bagnoli, L.; Temperini, A. Angew Chem. Int. Ed. 2003, 42, 3131. 